\title{
Precipitate coarsening and self organization in erbium-doped silica
}

Sckerl, Mads W.; Guldberg-Kjær, Søren Andreas; Poulsen, Mogens Rysholt; Shi, Peixiong; Chevallier, J.

Published in:

Physical Review B

Link to article, DOI:

10.1103/PhysRevB.59.13494

Publication date:

1999

Document Version

Publisher's PDF, also known as Version of record

Link back to DTU Orbit

Citation (APA):

Sckerl, M. W., Guldberg-Kjær, S. A., Poulsen, M. R., Shi, P., \& Chevallier, J. (1999). Precipitate coarsening and self organization in erbium-doped silica. Physical Review B, 59(21), 13494-13497.

https://doi.org/10.1103/PhysRevB.59.13494

\section{General rights}

Copyright and moral rights for the publications made accessible in the public portal are retained by the authors and/or other copyright owners and it is a condition of accessing publications that users recognise and abide by the legal requirements associated with these rights.

- Users may download and print one copy of any publication from the public portal for the purpose of private study or research.

- You may not further distribute the material or use it for any profit-making activity or commercial gain

- You may freely distribute the URL identifying the publication in the public portal 


\title{
Precipitate coarsening and self organization in erbium-doped silica
}

\author{
M. W. Sckerl, S. Guldberg-Kjaer, M. Rysholt Poulsen, and P. Shi \\ Mikroelektronik Centret, Technical University of Denmark, Building 345E, DK-2800 Lyngby, Denmark \\ J. Chevallier \\ Institute of Physics and Astronomy, University of Aarhus, DK-8000 Aarhus C, Denmark
}

(Received 19 January 1999)

\begin{abstract}
The influence of heat treatment at and above $1100{ }^{\circ} \mathrm{C}$ on thin erbium-rich silica layers embedded in silica has been studied experimentally by secondary ion-mass spectrometry and cross-sectional transmission electron microscopy. Redistribution of erbium atoms is observed at these temperatures, and formation of erbium-rich precipitates is seen to occur if the erbium concentration exceeds $\sim 0.01$ at. $\%$. These precipitates are observed to coarsen and subsequently dissolve with increasing annealing time. Moreover, self organization of precipitates has been observed in the form of layering of the precipitate ensemble. [S0163-1829(99)02518-7]
\end{abstract}

Erbium-doped silica glass is of great interest for use as amplifiers in optical telecommunications ${ }^{1}$ due to the $\mathrm{Er}^{3+}$-emission around $1550 \mathrm{~nm}$, a standard telecommunication wavelength. Of particular interest is the erbium-doped planar waveguide, ${ }^{2}$ since in the planar technology it is possible to integrate erbium-doped components with other devices on the same chip, and to allow for mass production and smaller component sizes.

However, a problem arises due to the higher erbium concentration needed when component sizes are reduced ${ }^{1}$. The solubility of erbium in silica is small and erbium-rich precipitates form at elevated temperatures. These precipitates drastically deteriorate the device efficiency due to an energytransfer upconversion process, which is caused by a dipoledipole interaction and hence becomes efficient when the average interion distance is small as it is within precipitates. When two neighboring ions are in the metastable state, one of them may transfer its excitation energy to the other, thus promoting the acceptor to a higher energy level. However, the acceptor quickly relaxes to the metastable state via phonon coupling. This process adds a nonradiative relaxation path from the metastable state to the ground state, thereby causing a decreased quantum efficiency.

Due to this highly undesirable effect, erbium precipitates in erbium-doped waveguides have been investigated experimentally by several groups. In particular the optical effects of precipitates have been studied in detail. In optical fibres, the fraction of erbium ions located in precipitates has been deduced from transmission, ${ }^{3,4}$ fluorescence, ${ }^{5}$ and laser-output measurements. ${ }^{6}$ In Refs. 7 and 8, erbium ions have been implanted into a variety of materials (oxide glasses, ceramic films, and silicon), and the implanted regions were studied by Rutherford backscattering spectrometry (RBS) and transmission electron microscopy (TEM). In Refs. 7-10, TEM micrographs show that precipitates form in silica after hightemperature annealing if the erbium concentration is sufficiently large (in the order of 0.1 at. \%).

However, up to now there have been no reports of studies of precipitate growth or self organization in erbium-doped silica, to our knowledge. In Ref. 11 diffusion of ionimplanted neodymium at $1100{ }^{\circ} \mathrm{C}$ in silica was studied by
RBS. The authors explained a lower diffusivity in the high concentration regions by the formation of precipitates. Moreover, these studies revealed an unexplained "curious" effect: Implantation peaks seem to have divided into two peaks during some of the heat treatments. Although less distinct, this is similar to observations shown in the present work and may be caused by the same mechanisms as those discussed below.

In this paper, we present a detailed study of precipitate coarsening in erbium-doped silica and, to our knowledge, the first confirmation of self organization via ripening of erbium in silica.

Layers of silica and erbium-doped silica were deposited on silicon wafers by a plasma-enhanced chemical vapor deposition technique. ${ }^{12}$ Halfway during the deposition of a $(\sim 1.6 \mu \mathrm{m})$ layer of pure silica, the erbium source was activated for a short time period thereby creating a thin $(\sim 25 \mathrm{~nm})$ erbium-doped layer. The substrate temperature was held at $300{ }^{\circ} \mathrm{C}$.

Two different compositions of the erbium-doped regions were produced, and measured by RBS to be 0.1 at. $\%$ and 0.4 at. \% erbium. Fractions of each wafer have been annealed at 1100,1140 , and $1185^{\circ} \mathrm{C}$ in a controlled atmosphere for different periods of time. A nitrogen atmosphere was used except for a few test samples, which were annealed in oxygen. No dependence of ambients on the erbium mobility was detected.

The broadening of the erbium-doped layer was investigated by secondary ion mass spectrometry (SIMS). Here, an oxygen ion beam was scanned over a $300 \times 600 \mu \mathrm{m}$ area in an angle of $60^{\circ}$ to the surface plane. Calibration between sputtering time and depth was done by measuring the crater depth with a profilometer. Cross-section samples for TEM were prepared by mechanical thinning followed by ion milling, and TEM investigations were done in a Philips CM20 microscope operating at $200 \mathrm{keV}$.

SIMS profiles of the dopant layer showed that erbium diffuses in the silica at temperatures at and above $1100{ }^{\circ} \mathrm{C}$. In Fig. 1 profile tails are plotted so as to produce a straight line in the case of a Gaussian distribution $\left(\log _{\mathrm{e}} N_{\mathrm{Er}} \propto X^{2}\right)$. Both the tail of the profile facing the surface (outer part) and 


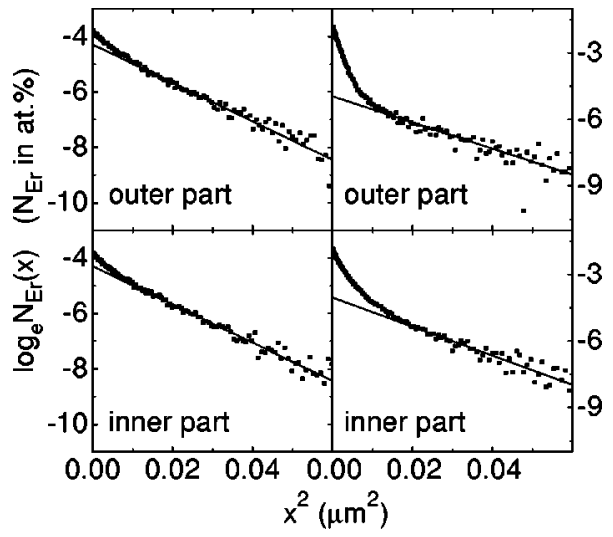

FIG. 1. Erbium concentration SIMS profiles for samples having different initial dopant levels: 0.1 at. \% (left) and 0.4 at. \% (right). Both samples annealed $21 \mathrm{~h}$ at $1100{ }^{\circ} \mathrm{C}$. Inner and outer part are the tail closest to and the one farthest away from the silicon substrate, respectively. A straight line, which corresponds to a Gaussian profile in this representation, has been fitted to the low concentration part of each profile $\left(N_{\mathrm{Er}} \leqslant 0.01\right.$ at. \%).

that facing the substrate (inner part) are shown for two different samples, having different initial dopant levels. By fitting the low concentration parts of such profiles, the diffusivity of erbium in silica has been deduced. ${ }^{13}$ If simple diffusional kinetics is assumed to govern the profile broadening in this one-dimensional geometry, a Gaussian shape would be expected. In Fig. 1 the low concentration part of the profiles resemble straight lines but deviations exist in the high concentration region. These deviations may be explained by the formation of precipitates, which are stable during the time of annealing and contain a large erbium concentration. Since both the erbium atoms located in the precipitates and those freely migrating are detected by SIMS, the concentration profiles deviate from a Gaussian shape. Clearly, the deviations are more pronounced for the sample with a high erbium concentration (right) than for that with a low erbium concentration (left), simply because more precipitates are formed at high concentrations.

In general, it was found that no precipitates were observed in regions where the erbium concentration was below 0.01 at. \%, which indicates that the solubility limit of erbium in silica is of this order of magnitude for the temperatures employed here.

A cross-sectional TEM (X-TEM) micrograph of a sample annealed for $3 \mathrm{~h}$ at $1140{ }^{\circ} \mathrm{C}$ is shown in Fig. 2(a). Indeed nanosized precipitates are formed in a $\sim 100 \mathrm{~nm}$ wide layer in the middle of the silica film, e.g., around the erbiumdoped region, and in this region SIMS spectra showed a strong deviation from a Gaussian-like diffusion profile. Energy dispersive $\mathrm{x}$-ray analysis spectra, obtained using a focused electron beam, confirmed that the precipitates are indeed erbium enriched. The precipitate size distribution is shown in Fig. 2(b) along with a Gaussian fit. The distribution maximum falls near its mean value, and has a close to Gaussian shape. According to coarsening theory for an infinitesized ensemble the distribution should be skewed towards smaller precipitate sizes. ${ }^{14}$ However, the microscope contrast may not be sufficient to observe the smallest precipitates. The mean precipitate diameter $d$ was found to be $10 \mathrm{~nm}$.

In general, the time evolution of the precipitate system

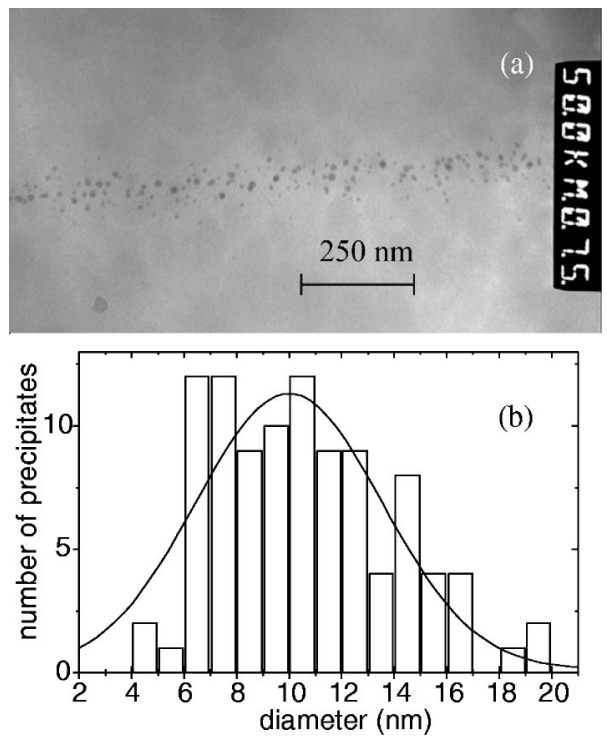

FIG. 2. (a) Cross-sectional TEM micrograph showing nanosized erbium-rich precipitates formed in the middle of a silica film. Same sample as in right side of Fig. 1 (0.4 at. \%) annealed $3 \mathrm{~h}$ at $1140{ }^{\circ}$ C. (b) Size distribution of precipitates in an ensemble of 99 precipitates. Mean diameter is $10 \mathrm{~nm}$.

may be separated into two overlapping physical stages: The nucleation stage and the precipitate coarsening stage. In the latter, the supersaturation decreases and causes an increase of the critical precipitate size below which precipitates are energetically unfavorable.

The effect of increased annealing time on the precipitate ensemble may be found by comparing Figs. 2 and 3, where the latter shows the sample after $24 \mathrm{~h}$ of annealing. Here, precipitates are bigger $(d=18 \mathrm{~nm})$ and the number density smaller, and hence follow an Ostwald ripening-like growth behavior. ${ }^{14,15}$ The driving force of Ostwald ripening is the significant contribution of the surface tension to the free energy, which is decreased by dissolving small precipitates and

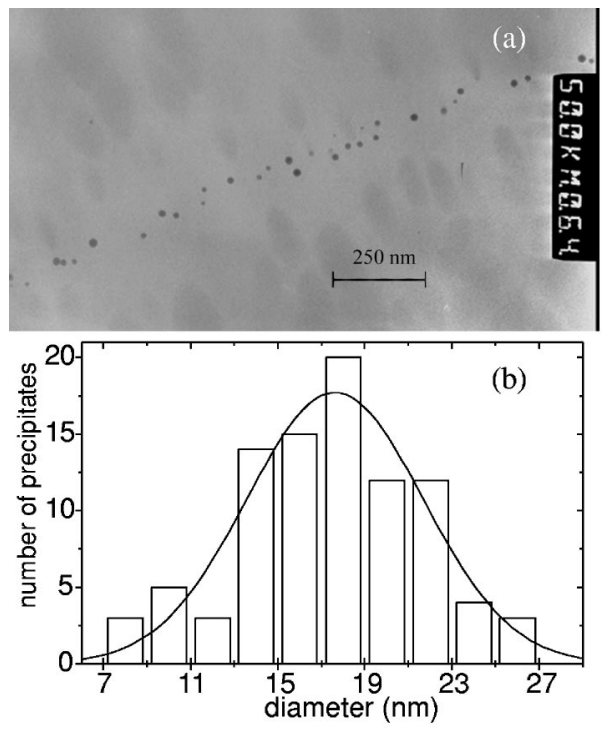

FIG. 3. (a) Same as Fig. 2, but sample annealed $24 \mathrm{~h}$ at $1140{ }^{\circ}$ C. (b) Size distribution of precipitates in an ensemble of 91 precipitates. Mean diameter is $18 \mathrm{~nm}$. 
forming larger ones. In this model, $d \propto D t^{1 / 3}$ (Ref. 14) in the coarsening stage of the time evolution. Here, $D$ is the diffusion coefficient. Hence, we should expect a factor of 2.0 difference (rather than 1.8) between the mean diameters after 3 and $24 \mathrm{~h}$ of heat treatment. However, quantification of the growth mechanism is complicated by the finite layer width of the Er-doped region, which implies a diffusion of erbium out of the precipitate region. This outward flux of atoms leads to a decreased growth speed and eventually to the dissolution of precipitates when the erbium concentration is everywhere below the solubility limit.

As a consequence of diffusion, the time evolution of finite precipitate ensembles may be augmented by a dissolution stage. Such dissolution of the precipitate system has been clearly observed in the present study. X-TEM analysis of the low-concentration sample ( 0.1 at. \%) showed a distinct layer of precipitates $(d=7 \mathrm{~nm})$ after $3 \mathrm{~h}$ annealing at $1140{ }^{\circ} \mathrm{C}$. However, no precipitates were visible after $3 \mathrm{~h}$ annealing at $1185^{\circ} \mathrm{C}$. This may be explained by the higher mobility at $1185^{\circ} \mathrm{C}$ causing the diffusion to proceed much more rapidly, and thus enabling the ensemble to reach the dissolution stage during the course of annealing. On the other hand, the sample annealed at $1140{ }^{\circ} \mathrm{C}$ only reached the coarsening stage in the same period of time. Since precipitates were visible after $1 \mathrm{~h}$ annealing at $1185{ }^{\circ} \mathrm{C}$, the observed dissolution cannot be explained by a temperature dependence of the solubility limit.

Interestingly, a finite dopant layer width may also under certain conditions manifest itself as a self organization of precipitates within the doped region. ${ }^{16}$ In parallel with the precipitate growth, precipitates start dissolving in the outer regions of the doped layer. The atoms emitted from the dissolving precipitates diffuse into the layer and cause precipitates within a diffusional screening distance to grow relative to those deeper inside the layer. Since larger precipitates grow at the expense of smaller ones, a layering of the precipitate ensemble has been initiated.

An example of such behavior is shown in Fig. 4, where the SIMS profile shows a clear double-peak feature indicating that precipitates have organized in two layers. Subsequent X-TEM studies confirmed a layering of the precipitate region, see Fig. 4(b). Here, the two arrows indicate the approximate position of the two precipitate layers, which may be difficult to see due to the stochastic nature of the precipitate distribution. However, the SIMS profile in Fig. 4(a), which represents an average over a 300 by $600 \mu \mathrm{m}$ area, clearly shows the two layers.

Such layering kinetics has previously been observed in systems such as $\mathrm{SiO}_{2}$ (Ref. 17) and Co (Ref. 18) in silicon, and $\mathrm{Cu}$ in silica, ${ }^{19}$ and the general mechanisms have been investigated theoretically. ${ }^{16,20}$ Of particular interest for the present study is the average distance $L$ between selforganized layers estimated in Refs. 20,21 to scale with the diffusional screening length $\lambda_{s}:{ }^{22}$

$$
\lambda_{s}=\left(4 \pi C_{p} R_{0}\right)^{-1 / 2} .
$$

Here, $C_{p}$ is the average number density of precipitates and $R_{0}$ represents a unique initial radius of precipitates.
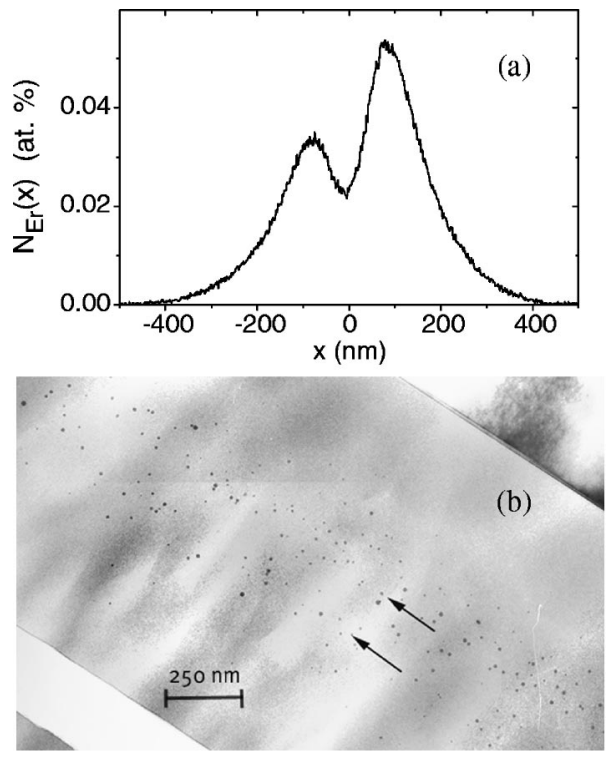

FIG. 4. (a) Double-peak feature in depth profile of sample annealed for $3 \mathrm{~h}$ at $1185^{\circ} \mathrm{C}$ as measured by SIMS. Width and concentration of initial dopant layer is $25 \mathrm{~nm}$ and 0.4 at. \%, respectively. Distance between the two peaks is $158 \mathrm{~nm}$. (b) Crosssectional TEM micrograph showing layering of erbium-rich precipitates in the same silica film as in (a). The two arrows indicate the approximate location of each layer. The distance between arrows is $\sim 165 \mathrm{~nm}$.

Using Eq. (1) we may give a rough estimate of $L$ for the precipitate system shown in Fig. 4. The glass thickness of the cross section shown in Fig. 4(a) was measured using the contamination-spot separation method in the TEM to be on the order of $100 \mathrm{~nm}$. With this we estimate the precipitate number density in Fig. 4(b) to be $C_{p}=10^{-6} \mathrm{~nm}^{-3}$ and by estimating (from Fig. 4) $R_{0}=5 \mathrm{~nm}$, we find $\lambda_{s}=119 \mathrm{~nm}$. This value of $\lambda_{s}$ should be compared with the interlayer distance $L=158 \mathrm{~nm}$ and $L=165 \mathrm{~nm}$ observed in Figs. 4(a) and 4(b), respectively. Thus a scale factor of 1.3 between $\lambda_{s}$ and $L$ is found, which is a factor of 2 smaller than that found by simulations in Ref. 20 . However, since this simple estimate indicates that the observed layer separation and $\lambda_{s}$ are of the same order of magnitude, we conclude that the selfstructuring mechanism found here possibly is identical to that described previously in Refs. 16,20. Moreover, since the layer separation is significantly larger than the width of the initial dopant region it is unlikely that the layering is caused by ripening of a spatial inhomogeneity in the initial precipitate size distribution.

In conclusion, we observe Ostwald ripening of erbiumrich precipitates in thin erbium-doped silica layers by SIMS and X-TEM. The predictions of the Ostwald ripening model for the time evolution of the average precipitate size agrees well with the present observations. After long annealing times the ripening process stops and dissolution of precipitates is observed, which is explained by the synergistic effects of precipitate growth and diffusion of erbium out of the erbium-enriched region.

Furthermore, this interplay of processes results in an interesting self-structuring of the precipitate ensemble, which is observed as a layering of the erbium-doped region. The 
inter-layer distance is found to compare well with predictions obtained by simulations of similar evolutions in other systems. Although the importance of this self organization is presently unclear, the process may have implications for erbium-doped waveguide systems of small dimensions.

We believe that these findings may lead to a more detailed understanding of the processes governing the evolution of nano-sized precipitates, and in particular of those leading to the disastrous consequences for erbium-doped optical amplifiers.

The authors thank L. C. Feldman for useful discussions and the Danish Materials Research and Development Program (MUP2) for financial support.
${ }^{1}$ E. Desurvire, Erbium-Doped Fiber Amplifiers: Principles and Applications, 1st ed. (Wiley, New York, 1994).

${ }^{2}$ P. G. Kik and A. Polman, MRS Bull. 24, 48 (1998).

${ }^{3}$ M. K. Davis, M. J. F. Digonnet, and R. H. Pantell, J. Lightwave Technol. 13, 120 (1995).

${ }^{4}$ E. Maurice, G. Monnom, B. Dussardier, and D. B. Ostrowsky, Opt. Lett. 20, 2487 (1995).

${ }^{5}$ R. S. Quimby, W. J. Miniscalco, and B. Thompson, J. Appl. Phys. 76, 4472 (1994).

${ }^{6}$ J. L. Wagener, P. F. Wysocki, M. J. F. Digonnet, and H. J. Shaw, Opt. Lett. 18, 2014 (1993).

${ }^{7}$ A. Polman et al., J. Appl. Phys. 70, 3778 (1991).

${ }^{8}$ A. Polman, J. Appl. Phys. 82, 1 (1997).

${ }^{9}$ K. Hattori et al., J. Appl. Phys. 80, 5301 (1996).

${ }^{10}$ L.-L. Lee and D.-S. Tsai, J. Mater. Sci. Lett. 13, 615 (1994).

${ }^{11}$ A. Shojai, G. T. Reed, and C. Jeynes, J. Appl. Phys. 25, 1280 (1992).

${ }^{12}$ B. Pedersen et al., in Proceedings of the 7th European Confer- ence on Integrated Optics, ECIO '95, edited by L. Shi, L. H. Spiekman, and X. J. M. Leijtens (Delft University Press, The Netherlands, 1995), p. 411.

${ }^{13}$ M. W. Sckerl et al. (unpublished).

${ }^{14}$ I. M. Lifshitz and V. V. Slyozov, J. Phys. Chem. Solids 19, 35 (1961).

${ }^{15}$ C. Wagner, Z. Elektrochem. 65, 581 (1961).

${ }^{16}$ V. A. Borodin, K.-H. Heinig, and S. Reiss, Phys. Rev. B 56, 5332 (1997).

${ }^{17}$ P. L. F. Hemment et al., Vacuum 36, 877 (1986).

${ }^{18}$ P. F. P. Fichtner, W. Jäeger, K. Rademacher, and S. Mantl, Nucl. Instrum. Methods Phys. Res. B 59/60, 632 (1991).

${ }^{19}$ R. H. Magruder III et al., J. Appl. Phys. 76, 708 (1994).

${ }^{20}$ S. Reiss and K.-H. Heinig, Nucl. Instrum. Methods Phys. Res. B 112, 223 (1996).

${ }^{21}$ L. A. Maksimov, A. I. Ryazanov, K.-H. Heinig, and S. Reiss, Phys. Lett. A 213, 73 (1996).

${ }^{22}$ A. D. Brailsford, J. Nucl. Mater. 60, 257 (1976). 